\title{
Single Component Sorption-Desorption Test Experimental Design Approach Discussions
}

The INL is a

U.S. Department of Energy

National Laboratory

operated by

Battelle Energy Alliance

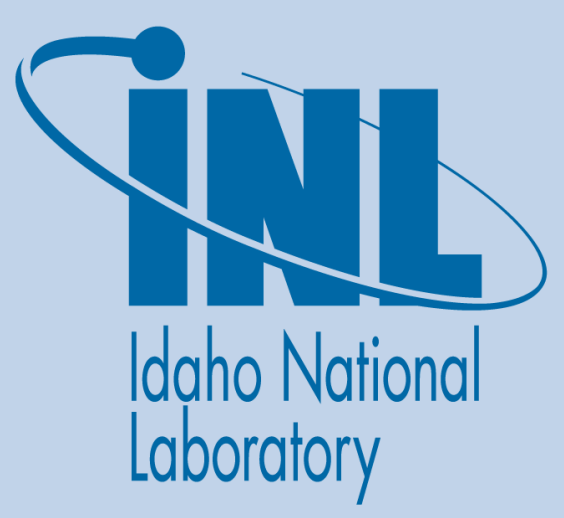

Jeffrey Berg

Pattrick Calderoni

Gary Groenewold

Paul Humrickhouse

Philip Winston

September 2011

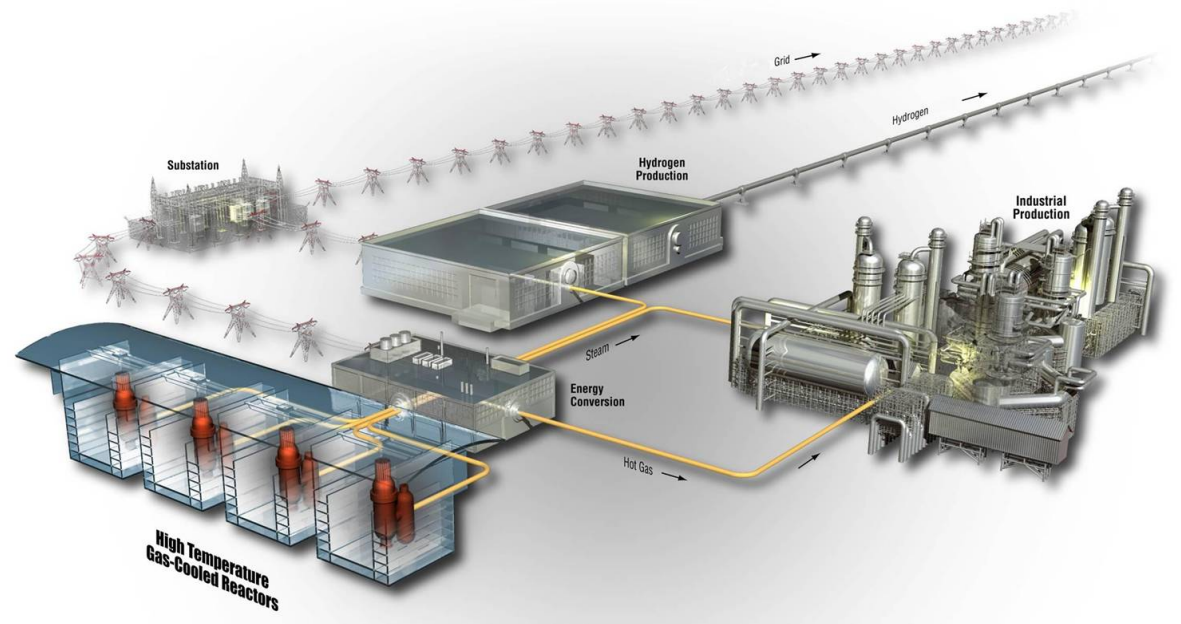




\section{DISCLAIMER}

This information was prepared as an account of work sponsored by an agency of the U.S. Government. Neither the U.S. Government nor any agency thereof, nor any of their employees, makes any warranty, expressed or implied, or assumes any legal liability or responsibility for the accuracy, completeness, or usefulness, of any information, apparatus, product, or process disclosed, or represents that its use would not infringe privately owned rights. References herein to any specific commercial product, process, or service by trade name, trade mark, manufacturer, or otherwise, does not necessarily constitute or imply its endorsement, recommendation, or favoring by the U.S. Government or any agency thereof. The views and opinions of authors expressed herein do not necessarily state or reflect those of the U.S. Government or any agency thereof. 


\title{
Single Component Sorption-Desorption Test Experimental Design Approach Discussions
}

\author{
Jeffrey Berg, Pattrick Calderoni, Gary Groenewold, \\ Paul Humrickhouse and Philip Winston
}

September 2011

Idaho National Laboratory

Next Generation Nuclear Plant Project

Idaho Falls, Idaho 83415

http://www.inl.gov

Prepared for the

U.S. Department of Energy

Office of Nuclear Energy

Under DOE Idaho Operations Office

Contract DE-AC07-05ID14517 

Next Generation Nuclear Plant Project

\section{Single Component Sorption-Desorption Test Experimental Design Approach Discussions}

INL/EXT-11-23259

Revision 0

September 2011

Approved by:

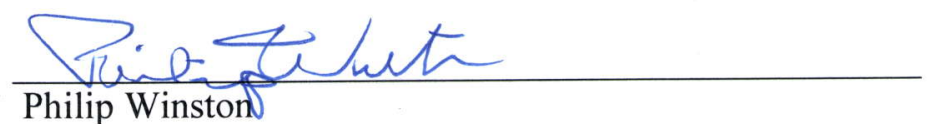

Engineer
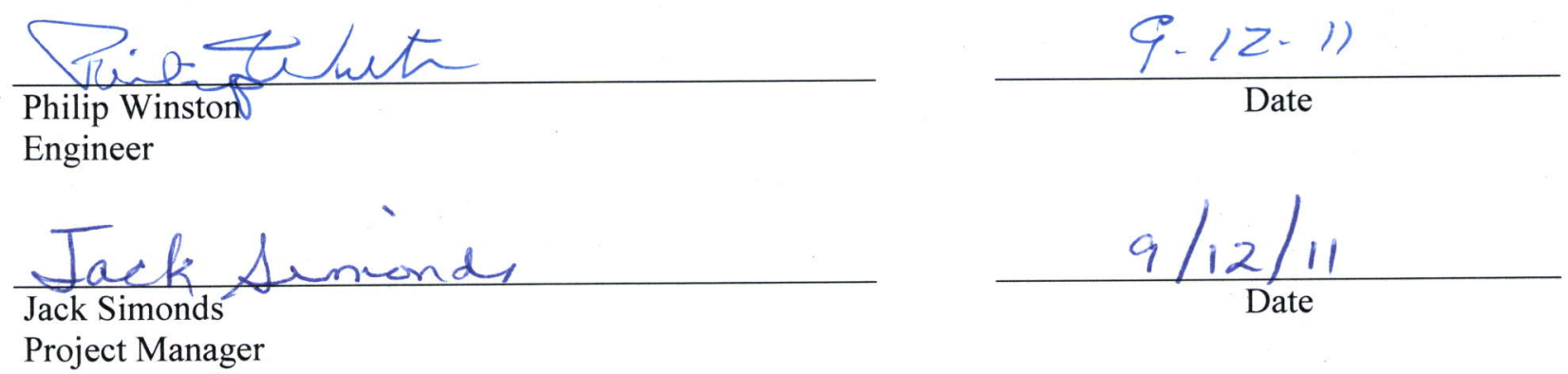


\section{EXECUTIVE SUMMARY}

A task was identified within the fission-product-transport work package to develop a path forward for doing testing to determine behavior of volatile fission products and to engage members of the NGNP community to advise and dissent on the approach. The following document is a summary of the discussions and the specific approaches suggested for components of the testing. Included in the summary are the minutes of the conference call that was held with INL and external interested parties to elicit comments on the approaches brought forward by INL participants. The conclusion was that an initial non-radioactive, single component test will be useful to establish the limits of currently available chemical detection methods and to evaluate source-dispersion uniformity. In parallel, development of a real-time low-concentration monitoring method is believed to be useful in detecting rapid dispersion as well as desorption phenomena. Ultimately, the test cycle is expected to progress to the use of radiotraced species because this method will allow the lowest possible detection limits. The consensus of the conference call was that there is no need for an incore test because the duct and heat exchanger surfaces that will be the sorption target will be outside the main neutron flux and will not be affected by irradiation.

Participants in the discussion and contributors to the INL approach were Jeffrey Berg, Pattrick Calderoni, Gary Groenewold, Paul Humrickhouse, Brad Merrill, and Phil Winston. Participants from outside the INL included David Hanson of General Atomics, Todd Allen, Tyler Gerczak, and Izabela Szlufarska of the University of Wisconsin, Gary Was, of the University of Michigan, Sudarshan Loyalka and Tushar Ghosh of the University of Missouri, and Robert Morris of Oak Ridge National Laboratory. 


\section{CONTENTS}

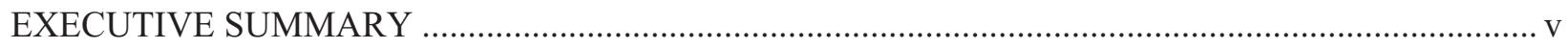

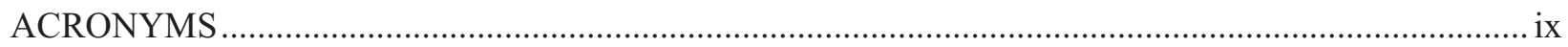

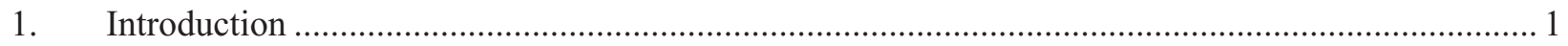

2. ANALYTICAL SOLUTION TO SILVER PHASE SORPTION …........................................ 3

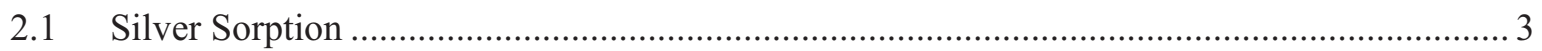

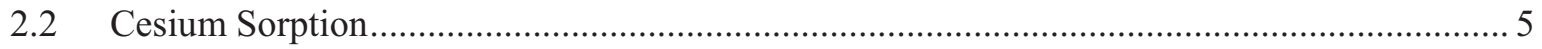

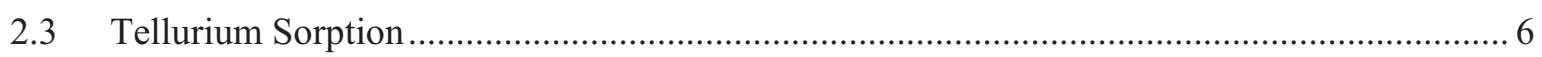

3. A PRESSURE CHAMBER APPROACH FOR MEASURING RADIONUCLIDE ISOTHERMS AT VERY LOW PARTIAL PRESSURES: SMALL CELL TEST

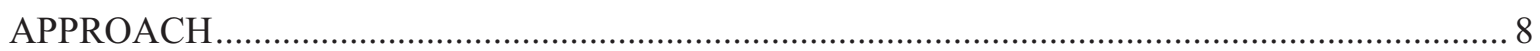

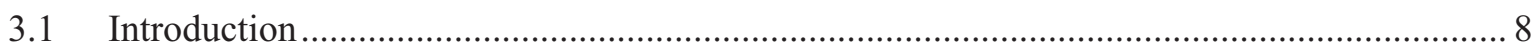

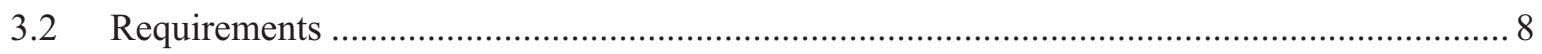

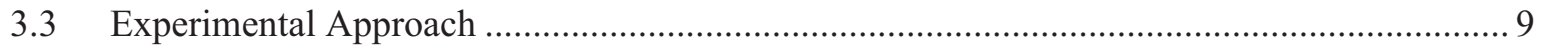

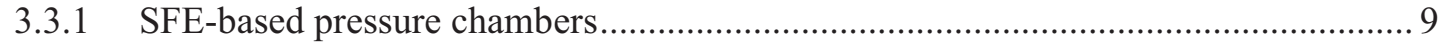

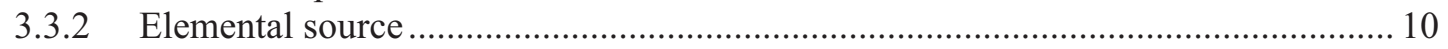

3.3.3 Spatial of the distribution of Ag during the experiment........................................... 11

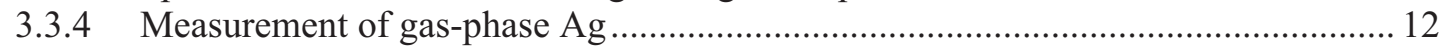

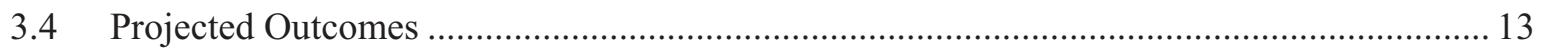

4. DETECTION BY ATOMIC ABSORPTION SPECTROMETRY: MEASUREMENT OF

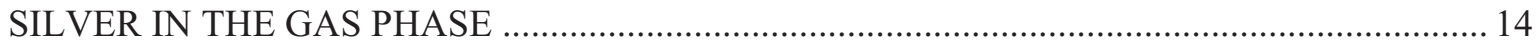

5. FISSION PRODUCT TRANSPORT TASK: SCOPING AG TEST IN THE SAFETY AND TRITIUM APPLIED RESEARCH FACILITY .......................................................... 16

6. INL-External Collaborator Conference Call Summary …..................................................... 20

Appendix A ROM Cost Estimate for Small Cell Test Activity .......................................................... 23

\section{FIGURES}

Figure 1. Silver Sorption Fraction of Surface Coverage..................................................................... 4

Figure 2. Silver Sorption Total Mass on Surface............................................................................. 4

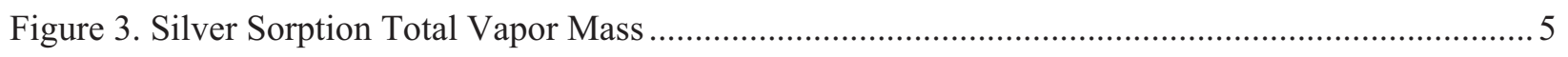

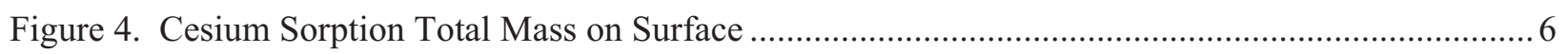

Figure 5. Cesium Sorption Total Vapor Mass ....................................................................................... 7

Figure 6. Photographs of small pressure chamber (internal volume $2.5 \mathrm{~cm}^{3}$ ). Device shown is used for supercritical fluid extraction experiments........................................................... 9 
Figure 7. Schematic diagram of the small pressure chamber, with path of laser pulse depicted in blue.

Figure 8. a.) YAG laser pulse impinging a concrete target. Images b. - e. are secondary ion mass spectrometry images. b.) Total ion image. c.) Cs image. d.) Na image. e.) M/z 43 (organic) image.

Figure 9. Simplified flow tube with a filament source for evaluating fraction of Ag in the gas phase and the spatial distribution of $\mathrm{Ag}$ in the tube 11

Figure 10. Long Path Atomic Absorption Sorption Detection Concept .............................................. 15

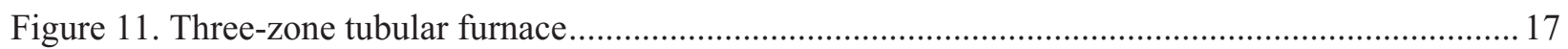

Figure 12. Thermal ionization systems standard filament performance ................................................ 18

Figure 13. Schematic of static tests for isotherm determination........................................................... 19

Figure 14. Cross sectional view of static tests for isotherm determination................................................ 19

\section{TABLES}

Table 1. Masses and concentrations of Ag in small pressure chambers at partial pressures from $10^{-9}$ to $10^{-15}$ atmospheres. . .9

Table 2. Required test tube length. 16 


\section{ACRONYMS}

AAS atomic absorption spectroscopy

ATR

Advanced Test Reactor

Dx

distance from filament

GFA graphite tube atomizer

HCL hollow cathode lamp

IAEA International Atomic Energy Agency

ICP-MS inductively coupled plasma mass spectrometer

INL Idaho National Laboratory

IRC INL Research Center

Nd:YAG neodymium-doped yttrium aluminum garnet (laser)

NGNP Next Generation Nuclear Plant

ORNL Oak Ridge National Laboratory

PMT photomultiplier tube

SFE super-critical fluid extraction

SIMS secondary-ion mass spectrometry

STAR Safety and Tritium Applied Research

VHTR very high temperature reactor

YAG yttrium aluminum garnet 


\section{EXPERIMENTAL PLAN FOR PRELIMINARY STUDIES LEADING TO GENERATION OF ISOTHERM DATA FOR AG IN THE PRIMARY COOLING LOOP OF AN HTGR}

\section{Introduction}

Information of the surface-gas phase partitioning of mobile/volatile fission products occurring in the primary cooling loop of the HTGR reactors is needed.

The proposed operating conditions for the very high temperature reactor (VHTR) are between 750 and $900^{\circ} \mathrm{C}$ at pressure between 7 and $11 \mathrm{MPa}$. This combination of high temperature and pressure will yield high thermal efficiency and heat for ancillary chemical processes. Imperfect fuel integrity may result in loss of some fission-product constituents that can complicate operation and introduce special concerns under accident conditions. Because of their mobility and volatility, Ag, Cs, I, Te, Eu, and Sr are elements of special concern. The fundamental fuel component is the TRISO particle which, in its current orientation, has shown limited effectiveness in retaining silver. Ag-110m has a relatively short half-life of 270 days, but its gamma-ray energy is comparable to that of Cs-137. Because it diffuses through the SiC layer of the TRISO particle, its presence in the primary cooling loop may represent a problem of concentration in cool zones of the heat exchanger. It may also be present as a poorly adhered surface film that could be a source of particulate in the event of a core cool down depressurization event. The bulk graphite, the presence of aerosol particles, and the entire primary circuit steel surface are all potential sinks of these fission products. For purposes of the current task, sorption of fission products on the heatexchanger steel has been selected for experimentation. Because Ag has anomalous behavior in the fuel material, it will be the focus of initial testing.

The quantity of deposition and the tenacity of adhesion is a matter of whether the fission product absorbs on active sites on the internal surfaces of the primary circuit by Van der Waals (electrostatic attraction), chemically reacts with the surface (covalent bonding), or is absorbed into the bulk material as an alloy or selectively moves along grain boundaries. These characteristics are not well established with respect to the species of interest at low partial pressures. It has been proposed that data on the sorption equilibria for Ag, Cs, and I on high-temperature stainless steels at partial pressures of $10^{-9}$ to $10^{-15}$ are needed (Hanson 2006, 911095) Data is available for deposition of Ag, I, and Cs on a tungsten substrate at a minimum partial pressure of $10^{-9}$.

The challenge of an experimental test program in this case is to develop fundamental characteristic data that can be generally applied. Past work with cesium indicated non-uniform deposition inside a test loop. Measurement indicated that several monolayers of radioactively tagged cesium built up in nonuniform manner, which yields an isotherm that is not specifically the classical Langmuir Type I isotherm.

To acquire the needed data, problems that need to be solved include: 1) modeling of expected dispersion and deposition using existing data and the required mass of source material for each test-cell design, 2) development of a technique for accurately depositing source material on a target or filament, 3) development of a means to uniformly disperse the source material in the sample chamber, 4) identifying a chemical or radiometric analysis method to determine surface distribution on a gross and local level, and 5) identifying a chemical or radiometric analysis method for determining gas-phase concentrations of the source material.

One of the first tasks is to design an experiment in which the adsorbate (in this case, a mobile fission product) can be deposited uniformly inside the test cell. One approach is to use a small-scale test that would use an existing test cell from a supercritical fluid oxidation test program. This is to test 
vaporization of a non-radioactive target material in a cell whose internal dimensions are $18 \mathrm{~mm}$ in diameter by $12 \mathrm{~mm}$ long. The test cell is fitted with quartz windows on either end. A laser aligned on a target centered in the cell would vaporize the target material. A gas line running to a mass spectrometer would allow sampling of the internal gas volume to determine the concentration of the analyte in the gas phase. The internal cylindrical surface would be lined with rings of the proposed heat exchanger steel to provide a sectional surface that can be removed for analysis to determine regional variation within the cell.

The progression of development is to do a conceptual design for a small-scale static test that can establish the techniques necessary for preparation of the sample so that it can be uniformly dispersed, as well as to test analytical methods for determining the presence and distribution of the adsorbate in the gas phase and on the target surfaces. Following validation of the dispersion and analytical techniques, testing in circulating systems can be performed. Once the circulating out-of-pile test has met the desired specifications, a loop for testing in a reactor system will be proposed.

The discussions that follow address 1) the chemical sorption model for Ag, 2) an experimental approach for performing initial single component static tests at the projected temperatures, pressures and partial pressures, 3) an alternate real-time analytical technique for tracking volatilization and sorption, and 4) an approach to scale up of the small-scale static tests using the STAR facility. 


\title{
2. ANALYTICAL SOLUTION TO SILVER PHASE SORPTION
}

\author{
Paul Humrickhouse
}

\subsection{Silver Sorption}

Historically, the equilibrium concentrations of gaseous and adsorbed silver have been described by the Langmuir isotherm:

$$
\Theta=\frac{a P}{1+a P}
$$

where $\theta$ is the fraction of monolayer coverage (varying from 0 to 1 ), a is a temperature dependent material constant, and $\mathrm{P}$ is the partial pressure of vaporized silver. It is apparent from the equation above that the Langmuir isotherm implies a limit on the adsorbed surface mass with increasing pressure, which is presumed to constitute a monolayer. The fractional coverage $\theta$ can be further described by

$$
\Theta=\frac{m_{s}}{A \Theta_{0}}
$$

where $\theta_{0}$ is the surface mass density (mass/area) of the monolayer, A is the surface area of the device, and $\mathrm{m}_{\mathrm{s}}$ is the is the total silver mass deposited. The parameter a (units 1/pressure) is given by an Arrhenius law:

$$
a=a_{0} \exp \left(\frac{-Q}{R T}\right)
$$

The isotherm is thus characterized by three material parameters: $\theta_{0}, \mathrm{a}_{0}$, and Q. Though the ultimate objective of the experiment campaign would be to independently determine these parameters; existing values can serve to guide the experiment design. Such data can be found in IAEA-TECDOC 978:

$\theta_{0}=0.2\left\{\mu \mathrm{g} / \mathrm{cm}^{2}\right\}$

$a_{0}=5.22 \times 10^{-7}\{1 / \mathrm{Pa}\}$

$Q=-2.54 \times 10^{-5}\left\{\mathrm{~Pa} \cdot \mathrm{m}^{3} / \mathrm{mol}\right\}$

The Test Specification for Fission Product Sorption Measurements (GA 911095) calls for measurements between 550 and $950^{\circ} \mathrm{C}$, over at least three orders of magnitude in partial pressures, below $10^{-9} \mathrm{~atm}$. Given this range of temperature and pressure, and the requirement of $10^{-12} \mathrm{~g}$ silver in the vapor phase required for measurement with the inductively coupled plasma mass spectrometer (ICP-MS), the required chamber volume can be determined. The ideal gas law gives

$$
V=\frac{m_{g} R_{A g} T}{P}
$$

where $\mathrm{R}_{\mathrm{Ag}}$ is the specific gas constant for $\operatorname{Ag} 110 \mathrm{~m}\left(0.07558\left(\mathrm{~Pa} \cdot \mathrm{m}^{3}\right) /(\mathrm{K} \cdot \mathrm{g})\right.$. For the maximum temperature $\mathrm{T}$ of $1223 \mathrm{~K}$, minimum partial pressure $\mathrm{P}$ of $10^{-12} \mathrm{~atm}\left(10^{-7} \mathrm{~Pa}\right)$, and silver vapor mass $\mathrm{m}_{\mathrm{g}}$ of $10^{-12} \mathrm{~g}$, the required volume is $\sim 945 \mathrm{~cm}^{3}$. This is the volume of a 2-in. diameter, $\sim 46 \mathrm{~cm}$ tube, which can be accommodated by present heaters.

Using the parameters for silver given in Equations (4) above, the fractional coverage is shown in Figure 1 below. The fractional coverage implies a total surface mass (Figure 2) according to Equation (2) above, for the surface area determined from the dimensions of the cylinder outlined in the preceding paragraph. In reality, the available surface area for adsorption will be higher due to roughness; the true surface area will have to be characterized prior to the experiment. 
Also shown below (Figure 3) is the vapor mass through the applicable range of partial pressure and temperature. The imposition of the $1 \mathrm{pg}$ limit at the low end of the pressure range is apparent. Note that the mass residing on the surface is far in excess of that in the vapor for all conditions. Thus, the curves in Figure 2 effectively identify the total mass that must be loaded to achieve the desired temperature and pressure conditions.

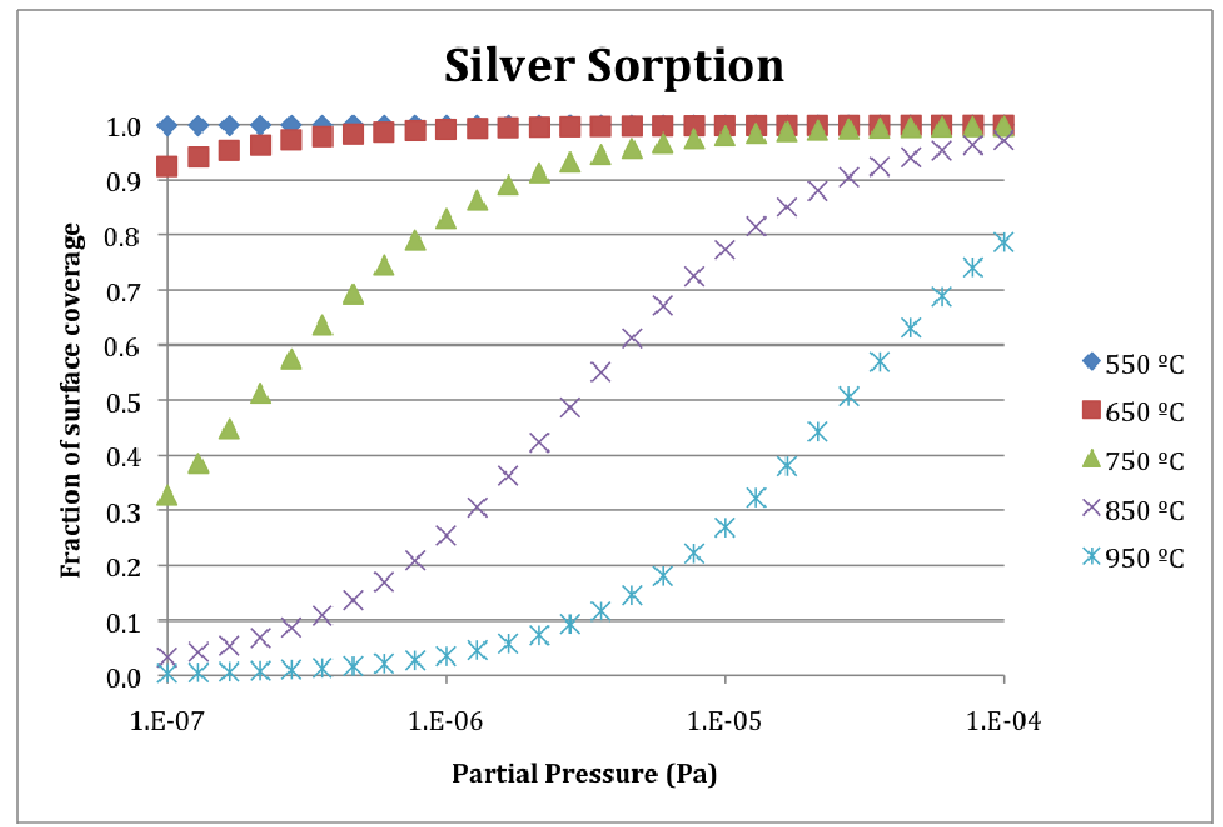

Figure 1. Silver Sorption Fraction of Surface Coverage

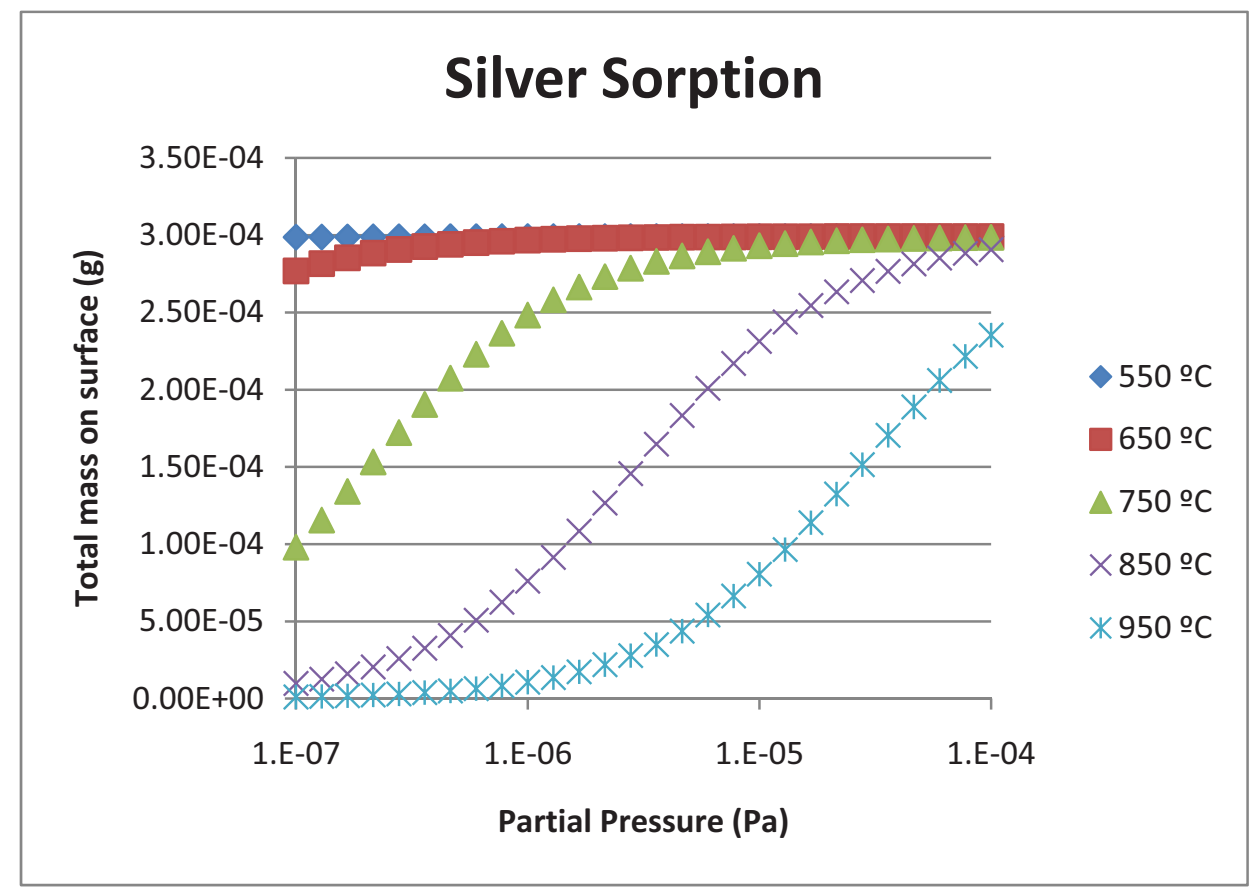

Figure 2. Silver Sorption Total Mass on Surface 


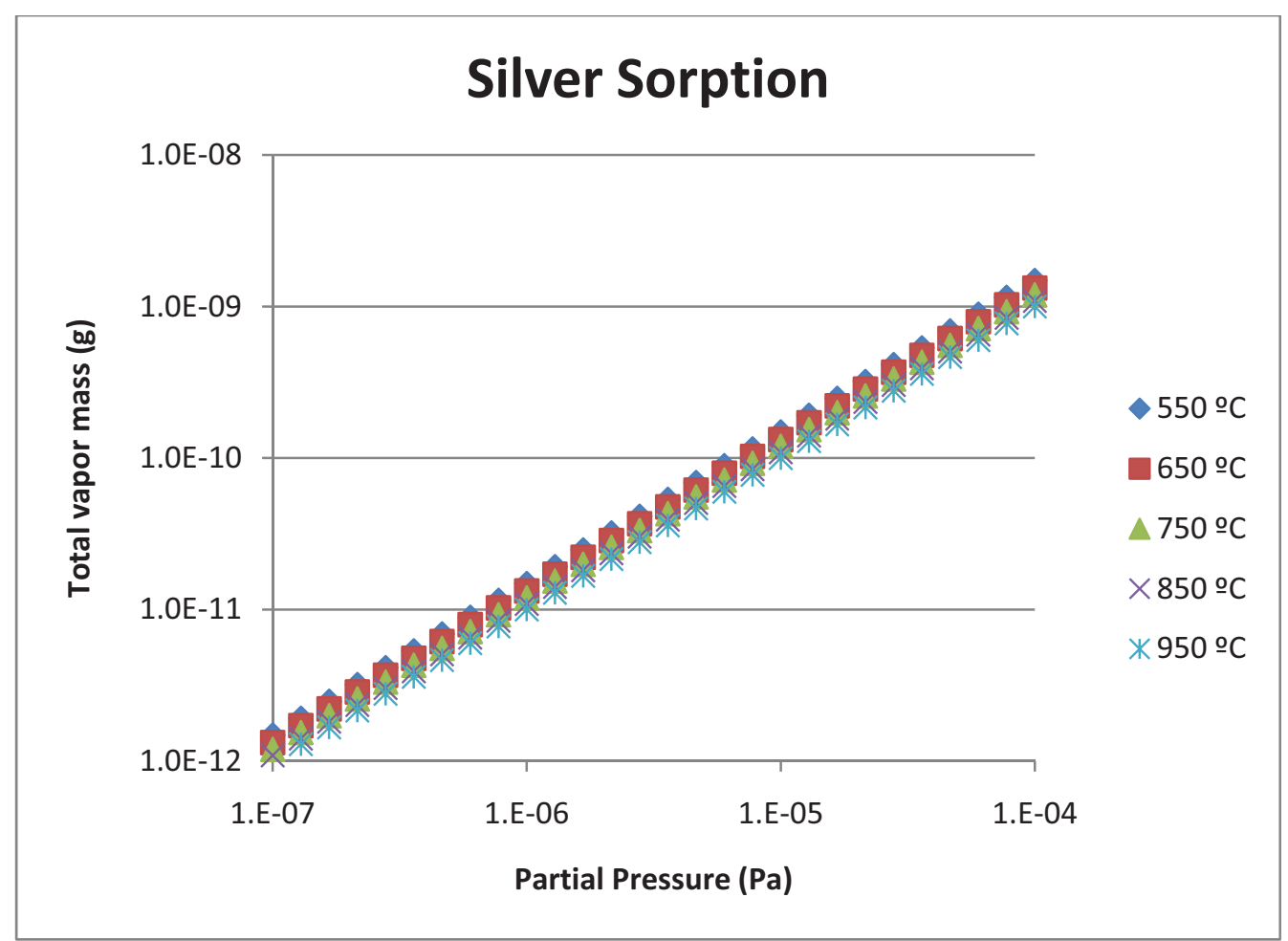

Figure 3. Silver Sorption Total Vapor Mass

\subsection{Cesium Sorption}

The Freundlich isotherm gives the partial pressure as a power law function of the surface mass density:

$$
P=b C^{n}
$$

where $\mathrm{b}$ is a (temperature dependent) constant, and $\mathrm{C}$ is the surface mass density (e.g. in $\mu \mathrm{g} / \mathrm{cm}^{2}$ ). Note that no limit corresponding to a monolayer is implied by this form of the isotherm. For VHTR applications, cesium sorption has been modeled with a sum of three terms of the type in Equation 6:

$$
P=\sum_{i=1}^{3} b_{i} C^{n_{1}}
$$

The inverse (surface mass as a function of partial pressure) cannot be obtained analytically from this form. The "constants" $b_{i}$ are Arrhenius functions of temperature:

$$
b_{i}=b_{i}^{0} \exp \left(\frac{-Q_{i}}{R T}\right)
$$

Thus, nine material constants are needed for this isotherm. The following are given in IAEA TECDOC-978:

$$
\begin{array}{r}
b_{1}^{0}=2.65 \times 10^{10}\left\{\mathrm{~Pa} /\left(\mu \mathrm{g} / \mathrm{cm}^{2}\right)\right\} \\
b_{2}^{0}=2.65 \times 10^{10}\left\{\mathrm{~Pa} /\left(\mu \mathrm{g} / \mathrm{cm}^{2}\right)\right\}^{3} \\
b_{3}^{0}=2.65 \times 10^{10}\left\{\mathrm{~Pa} /\left(\mu \mathrm{g} / \mathrm{cm}^{2}\right)^{8}\right\}
\end{array}
$$




$$
\begin{aligned}
Q_{1}=2.74 \times 10^{5}\left\{\mathrm{~Pa} \mathrm{~m}^{3} / \mathrm{mol}\right\} \\
Q_{2}=2.62 \times 10^{5}\left\{\mathrm{~Pa} \mathrm{~m}^{3} / \mathrm{mol}\right\} \\
Q_{3}=2.16 \times 10^{5}\left\{\mathrm{~Pa} \mathrm{~m}^{3} / \mathrm{mol}\right\} \\
n_{1}=1 \\
n_{2}=3 \\
n_{3}=8
\end{aligned}
$$

Assuming the same volume as for the silver experiment, and the same range of temperatures and pressures, the only parameter in Equation 5 that differs is the specific gas constant. It will be lower for cesium, so the $1 \mathrm{pg}$ vapor mass limit will still be satisfied. Once again, the surface mass far exceeds the vapor mass in this range of temperatures and pressures, and the surface mass shown below in Figure 4 is effectively the total mass required to achieve the desired conditions. The predicted vapor mass is shown in Figure 5.

\subsection{Tellurium Sorption}

There do not appear to be any existing data, or models, for tellurium sorption; no theoretical guidance can be given in this case regarding the necessary mass loading to achieve the desired partial pressures.

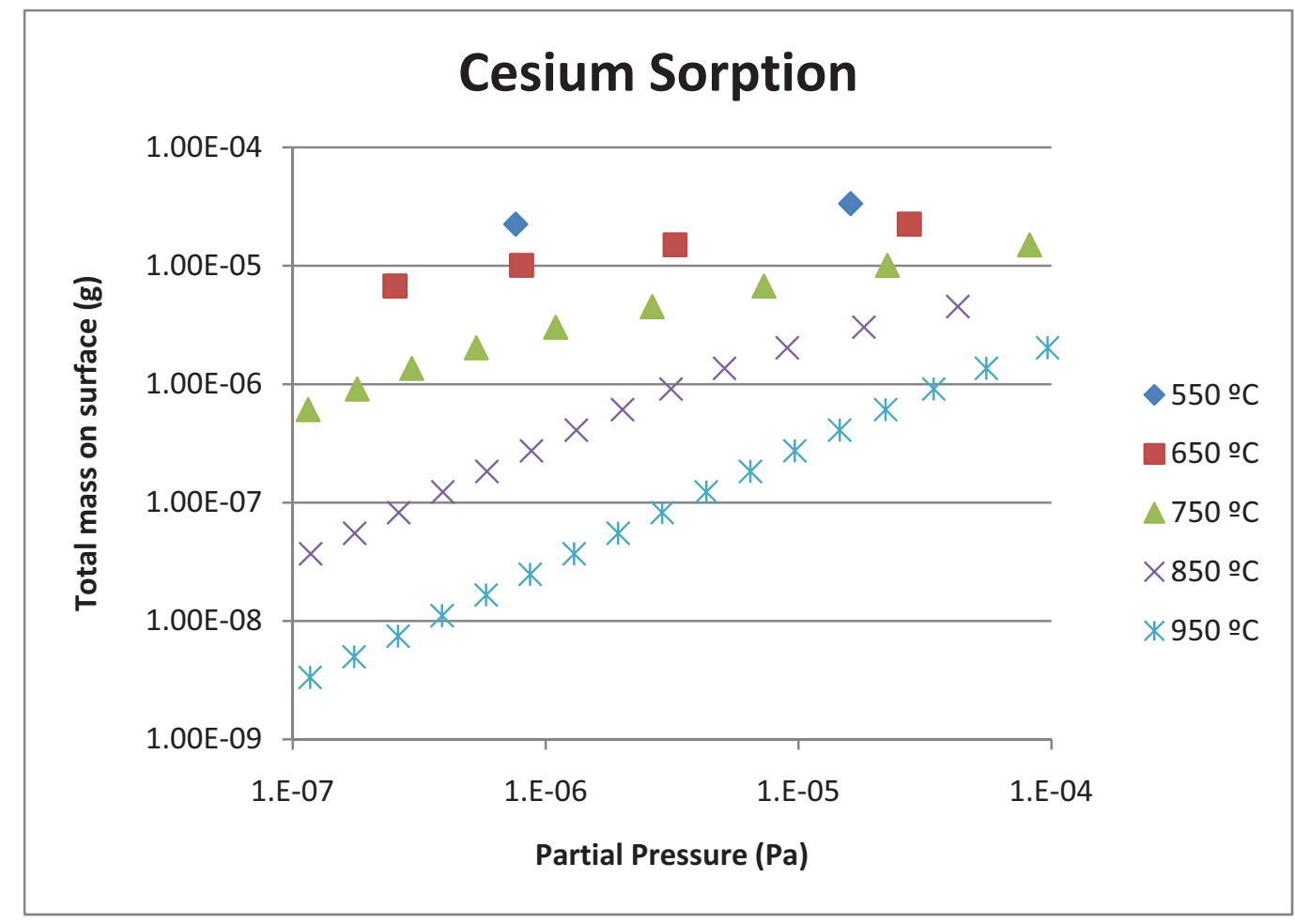

Figure 4. Cesium Sorption Total Mass on Surface 


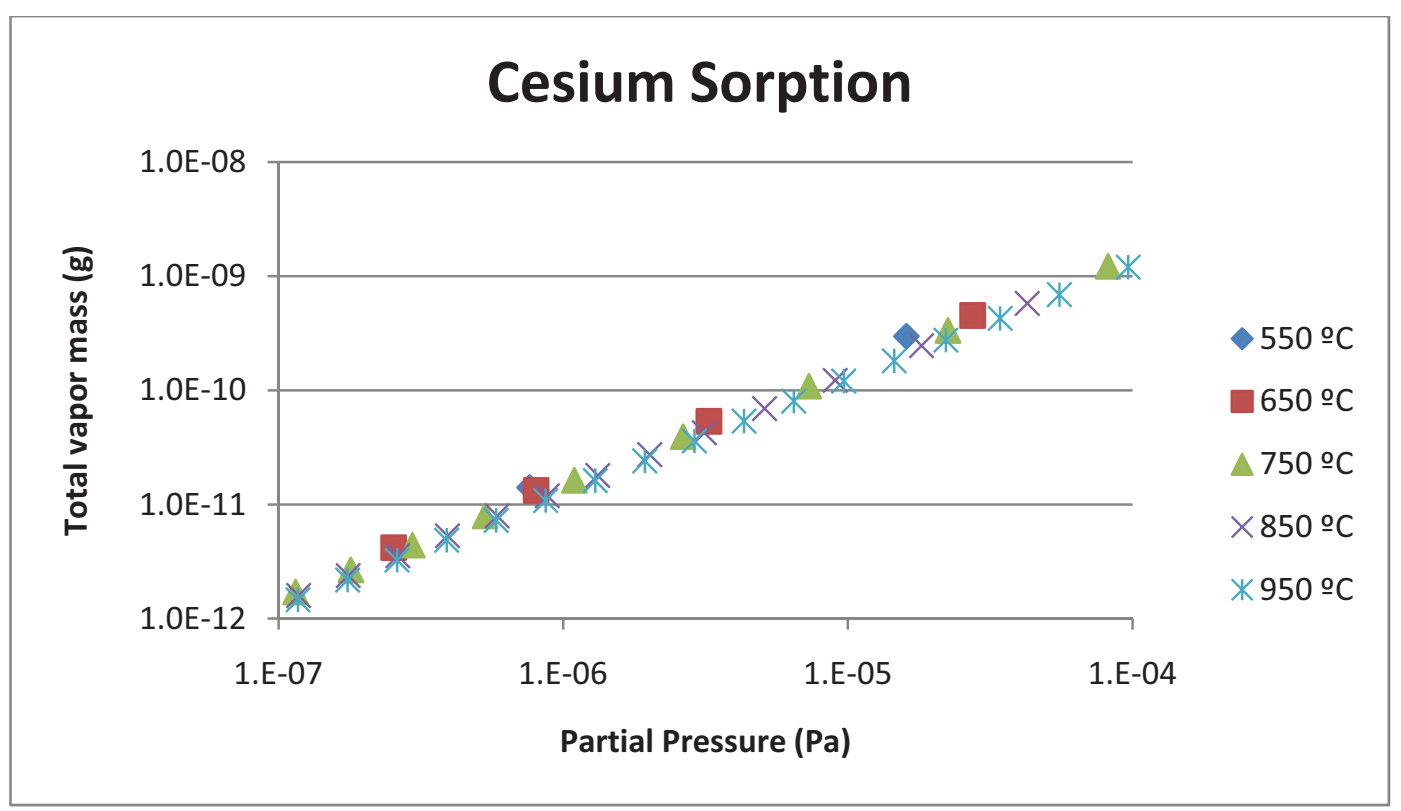

Figure 5. Cesium Sorption Total Vapor Mass 


\title{
3. A PRESSURE CHAMBER APPROACH FOR MEASURING RADIONUCLIDE ISOTHERMS AT VERY LOW PARTIAL PRESSURES: SMALL CELL TEST APPROACH
}

\author{
Gary S. Groenewold \\ Interfacial Chemistry \\ Idaho National Laboratory \\ 110221
}

\subsection{Introduction}

Data for Ag and several other radionuclides (Cs, Te and I) at low partial pressures are needed to predict dispersion within the primary cooling loop of HTGRs. Typical conditions of the cooling loop range from 50 to $90 \mathrm{~atm} \mathrm{He}(5-9 \mathrm{MPa})$ over a temperature range of $750-950^{\circ} \mathrm{C}$. However behavior under accident conditions is also of interest, where temperatures of $1800^{\circ} \mathrm{C}$ might be realized.

Under normal operating conditions, Ag-110m formed as a fission product will migrate through the TRISO fuel particle coatings and subsequently be transported through the primary cooling system. There is concern that deposition of $\mathrm{Ag}-110 \mathrm{~m}$ and other radionuclides could cause a radiation hazard to personnel performing periodic maintenance. Therefore, the ability to predict distribution in the cooling loop is desired.

Current modeling codes require knowledge of partitioning between the gas phase and the surfaces of interest; hence the codes need isotherms for $\mathrm{Ag}$ and the other radionuclides as input parameters. While $\mathrm{Ag}$ isotherms are known, a significant data gap exists over the range of $\mathrm{Ag}$ partial pressures from $10^{-9}$ to $10^{-15}$ atmospheres. The quantity of Ag that might adsorb on primary heat exchanger surfaces.

Proposed primary heat exchanger materials include Incoloy 800H, Inonel 617, and Haynes 230.

An experimental approach that would lead to determination of the Ag isotherms is described in this report.

\subsection{Requirements}

The most stringent challenge will be measuring Ag concentration at partial pressures down to $10^{-15}$ atmospheres. Considering a small, $2.5 \mathrm{~cm}^{3}$ pressure vessel the entire volume at a partial pressure of $10^{-9}$ atmospheres will contain only $2.7 \mathrm{pg}$ of $\mathrm{Ag}$ (Table 1), which is near the minimum detection limit of an inductively-coupled plasma mass spectrometer (ICP-MS). 
Table 1. Masses and concentrations of Ag in small pressure chambers at partial pressures from $10^{-9}$ to $10^{-15}$ atmospheres.

\begin{tabular}{|c|c|c|c|c|}
\hline $\begin{array}{c}\text { Partial } \\
\text { Pressure } \\
(\mathrm{atm})\end{array}$ & $\begin{array}{c}\text { Temp. } \\
\left({ }^{\circ} \mathrm{C}\right)\end{array}$ & $\begin{array}{c}\text { Chamber } \\
\text { Vol. } \\
(\mathrm{cc})\end{array}$ & $\begin{array}{c}\text { Mass in } \\
\text { Chamber } \\
(\mathrm{g})\end{array}$ & $\begin{array}{c}\text { Concentration in } \\
\text { Chamber } \\
(\mathrm{g} / \mathrm{cc})\end{array}$ \\
\hline $1.0 \times 10^{-9}$ & 950 & 2.5 & $2.7 \times 10^{-12}$ & $1.1 \times 10^{-12}$ \\
\hline $1.0 \times 10^{-12}$ & 950 & 2.5 & $2.7 \times 10^{-15}$ & $1.1 \times 10^{-15}$ \\
\hline $1.0 \times 10^{-15}$ & 950 & 2.5 & $2.7 \times 10^{-18}$ & $1.1 \times 10^{-18}$ \\
\hline $1.0 \times 10^{-9}$ & 950 & 60.0 & $6.4 \times 10^{-11}$ & $1.1 \times 10^{-12}$ \\
\hline $1.0 \times 10^{-12}$ & 950 & 60.0 & $6.4 \times 10^{-14}$ & $1.1 \times 10^{-15}$ \\
\hline $1.0 \times 10^{-15}$ & 950 & 60.0 & $6.4 \times 10^{-17}$ & $1.1 \times 10^{-18}$ \\
\hline
\end{tabular}

Experiments that can be conducted with non-radiological nuclides are desired, because the cost and complexity of conducting radiological experiments would be significantly higher. Experiments must come to equilibrium in a reasonable period of time.

\subsection{Experimental Approach}

\subsubsection{SFE-based pressure chambers}

The experimental approach is based on small pressure chambers, patterned after super-critical fluid extraction (SFE) cells that are currently in use at the INL Research Center (IRC). The cells are appropriate for these tests because the experiments will require high pressure and high temperature. Experiments to operate the SFE cells at these temperature and pressure regimes have already been conducted.

The small pressure chambers consist of a cylindrical barrel with two flanged end-seals (Figure 6). The chamber is sealed using a torque wrench to compress either gold or Grafoil seals that hold the windows in place. At present, the chambers are fitted with cartridge heaters that can heat the chamber to about $450^{\circ} \mathrm{C}$. The chamber can be operated in a furnace to reach the higher end of proposed operational temperatures $\left(950^{\circ} \mathrm{C}\right)$.

The chamber can be equipped with multiple ports for pressurization and sample collection. This type of chamber will accommodate pressures well in excess of the 90 atmospheres stipulated by the experimental requirements.

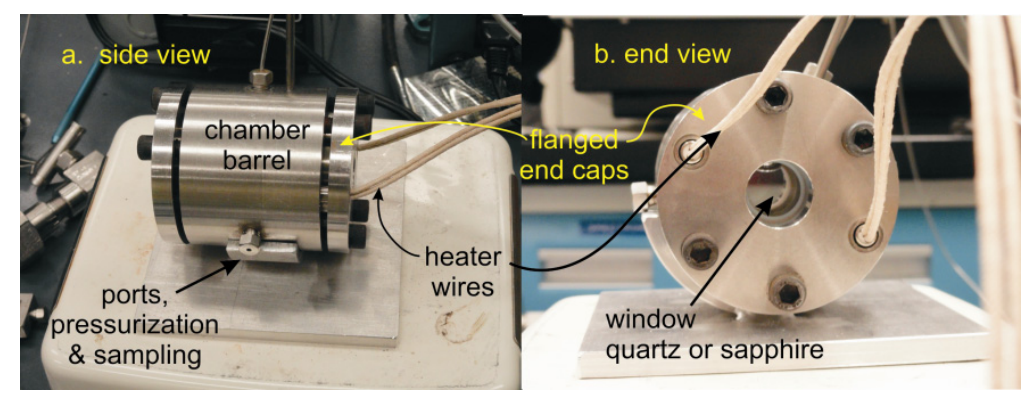

Figure 6. Photographs of small pressure chamber (internal volume $2.5 \mathrm{~cm}^{3}$ ). Device shown is used for supercritical fluid extraction experiments. 
The small pressure chambers can be easily disassembled, which enables surface analysis of the interior walls after the isotherm experiments. The window, which is typically either quartz or sapphire, enables either optical investigation of the gaseous contents of the chamber or laser ablation to volatilize the element of interest.

\subsubsection{Elemental source}

At partial pressures of $10^{-12} \mathrm{~atm}$, extremely long time periods (up to a month or longer) are needed to reach equilibrium. It is hypothesized that this is to due to very slow desorption kinetics from the inherent low volatility of the elements of interest and the very short mean-free path in the pressurized $\mathrm{He}$ atmosphere. In the 750 to $950^{\circ} \mathrm{C}$ temperature range, $\mathrm{Ag}$ and the other elements may volatilize slowly without any external energy source.

A strategy for overcoming the slow desorption kinetics is to use laser ablation, irradiating a $\mathrm{Ag}$ (or other element) -coated target with a high-intensity laser pulse so that the entire quantity of $\mathrm{Ag}$ is volatilized. The yttrium-aluminum-garnet (YAG) laser to be used for these experiments is currently in use at the IRC, and there is considerable in-house expertise. Experiments to operate the YAG laser with the SFE cell have already been designed, reviewed, and conducted.

Because the total amount of Ag used in the experiments may be small, it is proposed to quantitatively deposit Ag onto a laser target using electrochemical deposition. The targets are envisioned to be roughly 2 $\times 2 \mathrm{~mm}$ coupons, spot-welded onto a wire sample holder. The targets will be coated with wax to enable electroplating of only the side that will be irradiated using the laser. The SFE cell will be modified by drilling small holes that will accommodate Ag-plated targets (Figure 7).

The quantity of Ag to be deposited may be on the order of nanograms: a one monolayer coating over the interior surface of the $3.05 \mathrm{~cm}^{3}$ chamber $\left(1.8 \mathrm{~cm}^{2}\right)$ would correspond to 33 nanograms, while the mass associated with a partial pressure of $1 \times 10^{-9}$ atmospheres at $298 \mathrm{~K}$ would be 14 picograms.

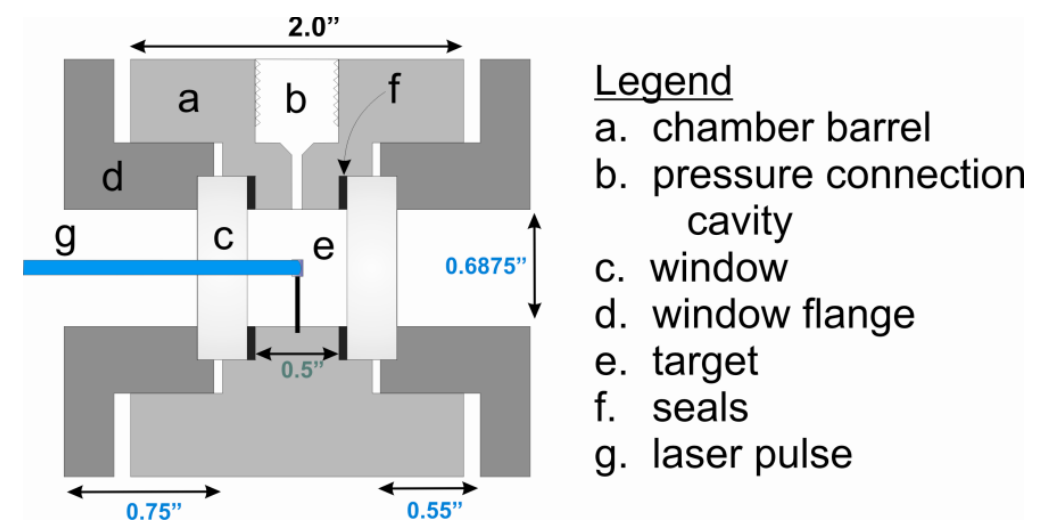

Figure 7. Schematic diagram of the small pressure chamber, with path of laser pulse depicted in blue.

The laser to be used is a neodymium doped YAG device, built by Opotek and currently housed at the IRC. The laser fundamental wavelength is $1064 \mathrm{~nm}$, and it delivers $850 \mathrm{~mJ}$ at this wavelength. The laser also delivers a visible line at $532 \mathrm{~nm}$, and two UV lines at 355 and $266 \mathrm{~nm}$; the pulse powers of these lines are 500, 150 and $150 \mathrm{~mJ}$, respectively. The laser can also be tuned, using the optical parametric oscillator, to produce any wavelength desired, and power values achieved using this are in the 10-30 mJ range. Values in excess of $100 \mathrm{~mJ}$ are sufficient to quantitatively volatilize the amount of $\mathrm{Ag}$ used in these experiments (33-330 ng). The effect of a $150 \mathrm{~mJ}$ pulse on concrete (Figure 8, a) results in removal of the metals from the top layer of the material. Subsequent analysis using secondary-ion mass 
spectrometry of the top layer shows complete removal of cesium (Figure 8, c.) and near-complete removal of sodium (Figure 8, d).

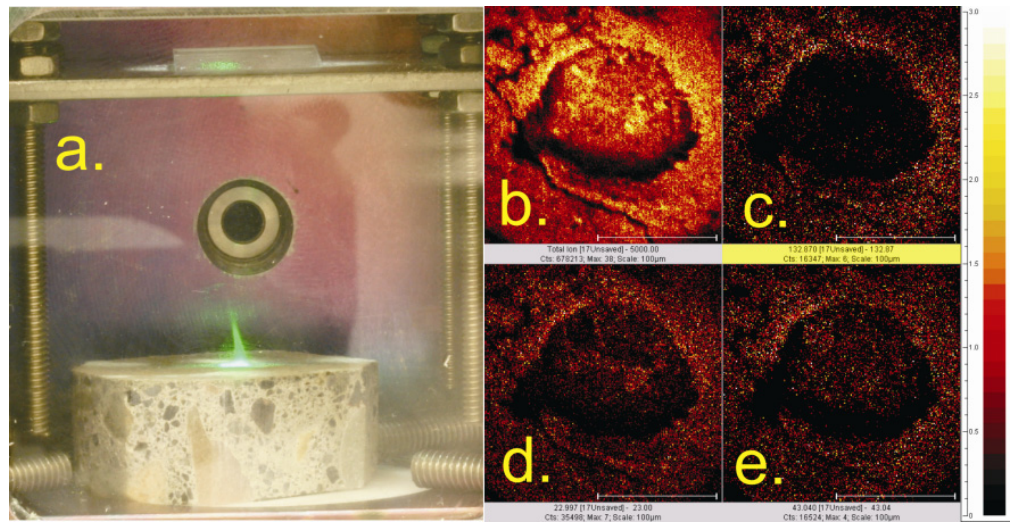

Figure 8. a.) YAG laser pulse impinging a concrete target. Images b. - e. are secondary ion mass spectrometry images. b.) Total ion image. c.) Cs image. d.) Na image. e.) M/z 43 (organic) image.

Laser pulses will be directed through the pressure chamber window along the chamber axis (Figure 8). Laser targeting is conducted by directing a low intensity IR laser along the optical path, and measuring transmittance using a laser camera. The laser camera can also record the fraction of light traversing the Ag target.

Other volatilization alternatives will be considered. For example, a filament loaded with the requisite mass of Ag could be resistively heated to volatilize the Ag in a chamber experiment similar to that depicted in Figure 9. Disassembly of such an experiment could evaluate deposition as a function of distance from filament (Dx), which would provide valuable phenomenological deposition behavior. Such an experiment may develop additional appeal, i.e., it doesn't require a laser. Nevertheless, the laser pressure-chamber experiment are the most attractive at this point.

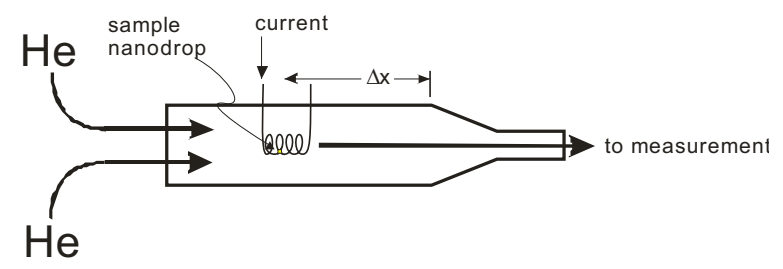

Figure 9. Simplified flow tube with a filament source for evaluating fraction of $\mathrm{Ag}$ in the gas phase and the spatial distribution of $\mathrm{Ag}$ in the tube.

\subsubsection{Spatial of the distribution of Ag during the experiment}

The predominant result of laser desorption of Ag from the targets within the chamber is hypothesized to be migration of the Ag from the target to the walls. If volatilization is quantitative and diffusion is fast, then it is hypothesized that the Ag will be uniformly coated over the interior of the chamber. This will be evaluated after the experiment's termination, which will involve evacuation of the residual atmosphere through the ports in the chamber. One of three options will be used to measure distribution of $\mathrm{Ag}$ within the small pressure chamber. The simplest approach involves leaching the Ag from the components of the chamber after disassembly. The Ag can likely be oxidized and dissolved from the surfaces of the windows, the chamber barrel, the seals and the target using a $\mathrm{HNO}_{3}$ solution that can then be analyzed directly using ICP-MS. The pressurization/evacuation port and associated tubing will also be analyzed 
using the same approach; Ag deposited in these areas may be indicative of the fraction residing in the vapor phase at the end of the experiment.

The second option for evaluating distribution of Ag within the chamber will be to insert metal coupons that will function as sorptive sinks for Ag. The advantage of these is that they can be easily removed from the chamber in the event more aggressive leaching is needed or if a direct surface analysis is desired. A variety of coupon configurations is conceivable, including lining the inside of the chamber barrel with concentric rings that can be removed and then leached and analyzed. The advantage of this particular configuration is that variations in distribution as a function of distance from the source can be discerned.

The third option is to remove sink coupons for imaging analysis using time-of-flight secondary-ion mass spectrometry (SIMS). This has the advantage of providing elemental distributions to a spatial resolution of several microns and would be beneficial for examining the target and sink coupons both before and after laser pulses. An example of both the imaging capability and the laser power are provided in Figure 8, b-e, which show the effect of laser irradiation on a concrete coupon. The detection limit for $\mathrm{Ag}^{+}$using the imaging SIMS is a small fraction of a molecular layer, which will enable tracking of the silver.

\subsubsection{Measurement of gas-phase Ag}

Measurement of the Ag residual in the gas phase represents the real challenge of this research effort, primarily because of the fact that concentrations at $10^{-9}$ atmospheres and lower are at or below detection limits using non-radiometric methods. Initially, however, capturing Ag in the atmosphere after an experiment has been performed should be achievable. At $10^{-9}$ atmospheres, tens of picograms should be present in the gaseous atmosphere of the $3 \mathrm{~cm}^{3}$ pressure chamber. At the conclusion of a partitioning experiment, the He atmosphere can be released via the evacuation port, and then trapped. Some or all of the Ag in the gas may adsorb to the walls of the transfer tubing, and it may be possible to measure this by leaching the tubing and then analyzing the leachate. Alternative views suggest that if the rate of venting is rapid, the gaseous Ag may exit the evacuation tubing without condensing, which in principle would allow trapping for later analysis. Approaches for trapping the Ag have not yet been identified; however, sparging into a small volume of $\mathrm{HNO}_{3}$ should function to efficiently capture the $\mathrm{Ag}$ in a medium compatible with ICP-MS analysis. Other options for trapping Ag that will be considered include venting through a baffled cold trap or utilization of materials like sorbent carbon or zeolites that would efficiently capture Ag, but would subsequently require extraction prior to analysis.

The total mass of Ag present in the volume of the $3.05 \mathrm{~cm}^{3}$ chamber at $10^{-9}$ atmospheres partial pressure is $14 \mathrm{pg}$, a quantity detectable using the ICP-MS instruments. However this is only about an order of magnitude above the detection limit of the instruments, which implies that only a fraction of the desired partial pressure range will be probed (to $\sim 10^{-10}$ atmospheres). A conceptually easy approach for evaluating partitioning at lower partial pressures is to use a larger volume chamber; a $60 \mathrm{~cm}^{3}$ chamber would push the partial pressures to be measured into the mid- $10^{-12}$ atmosphere range, and fabrication of chambers having volumes approaching one liter is readily achievable. This would provide measurement of masses of Ag corresponding to partial pressures approaching $10^{-13}$ atmospheres.

Measurement of $\mathrm{Ag}$ derived from samples having partial pressures in the $10^{-14}-10^{-15}$ atmosphere range will require different approaches. Use of radio-Ag might provide a viable strategy. Using radiosilver would add to the cost of the experiments, but it might be the best path forward for the very low partial pressure measurements. It should be noted that manipulation of the experiment learned in the nonradiological experiments will be a pre-requisite for eventually using radio-silver. 
An altogether different approach would be to take the He atmosphere directly into the ICP-MS torch, and perform the analysis in on-the-fly mode. In principle, this is possible, but would require locating the pressure chamber and laser proximate to the ICP-MS instruments, which would be an involved task given the safety considerations associated with operation of a laser and a high pressure chamber. However, it would obviate the need for extracting the device used for collection of the gaseous Ag. A potential limitation is that the approach does not allow for any sample concentration, as does the trapping-ICP-MS strategy described above. A second option might be in situ atomic absorption and direct analysis of the He atmosphere using the ICP-MS. A detailed evaluation of this strategy has not yet been conducted.

\subsection{Projected Outcomes}

Conduct of the experiments described is expected to provide isotherm information at the higher partial pressure values of interest, and should provide that added benefit of evaluating Ag distribution in the pressure chambers. The small size of the experiment should enable conduct of multiple measurements, which is important because analytical precision will be poorer if the measurements are at or near detection limits.

Another valuable outcome will be mastery of the pressure chamber and YAG laser setup, which will be required for eventually conducting experiments using radio-silver.

It is also expected that much will be learned with regard to trapping gas-phase metals present in the He atmosphere within the pressure cell. In fact, the measurement of small masses of silver derived from the helium samples is principally dependent on the developed ability to a) capture and concentrate $\mathrm{Ag}$ from the He atmosphere, and b) leach the Ag from whatever trap is used into a minimal sample volume. 


\title{
4. DETECTION BY ATOMIC ABSORPTION SPECTROMETRY: MEASUREMENT OF SILVER IN THE GAS PHASE
}

\author{
Jeffrey F. Berg \\ Chemist, Analytical Laboratory \\ February 9, 2011
}

An attractive approach to doing in-pile testing with real-time analysis of the sorption process would be to utilize atomic absorption spectroscopy (AAS) for the determination of silver (Ag) atoms in the gas phase. The design would be a simple single-beam atomic absorption spectrometer, using the pressure tube as an atomization source. Assuming that the Advanced Test Reactor (ATR) is the baseline idea for an incore test, the pressure tube would be approximately 48 inches long. It would have a coaxial Re filament that would have uniform known deposition of $\mathrm{Ag}$ onto its entire length. The thermal atomization of $\mathrm{Ag}$ atoms is accomplished by passing current through the filament. The pressure tube end flanges would be fitted with quartz windows through which a light beam of monochromatic radiation from a line source would be passed. The line source would be a silver hollow cathode lamp (HCL). The neutral ground state silver atoms in the gas phase would absorb this discrete radiation $(328.1 \mathrm{~nm})$ and thereby reduce the beam intensity or transmittance. The light would be received at the far end of the tube through its corresponding window and focused with a lens into a monochromator with a spectral bandpass of 0.1 to $2 \mathrm{~nm}$, where the atomic line of interest is isolated. The attenuation of the source radiation by the silver atomic vapor is detected and amplified by a photomultiplier tube (PMT). The analytical signal is processed to yield an absorbance reading, which is proportional to the silver concentration in the light path. The typical sensitivity (Ag at $328.1 \mathrm{~nm}$ ) for a $3 \mathrm{~cm}$ path length graphite tube atomizer (GFA) AAS instrument is 0.2 pg at the $1 \%$ absorbance level ${ }^{*}$. The long $(122 \mathrm{~cm})$ path length of the atomization tube provides the increased sensitivity required to measure the extremely low silver concentration. Additional sensitivity could be achieved with a two-pass beam design using mirrors to double the path length, if desired.

- $\quad$ Light source-Ag HCL

- Lens between Ag HCL and Pressure Tube and monochromator and Pressure Tube.

- Detector-PMT

- Signal Processor-Absorbance Readout.

\footnotetext{
* Spectrochemical Analysis, James D. Engle and Stanley R. Couch, Prentice Hall, Englewood Cliffs, New Jersey, 1988, Table $10-3$, page 300.
} 


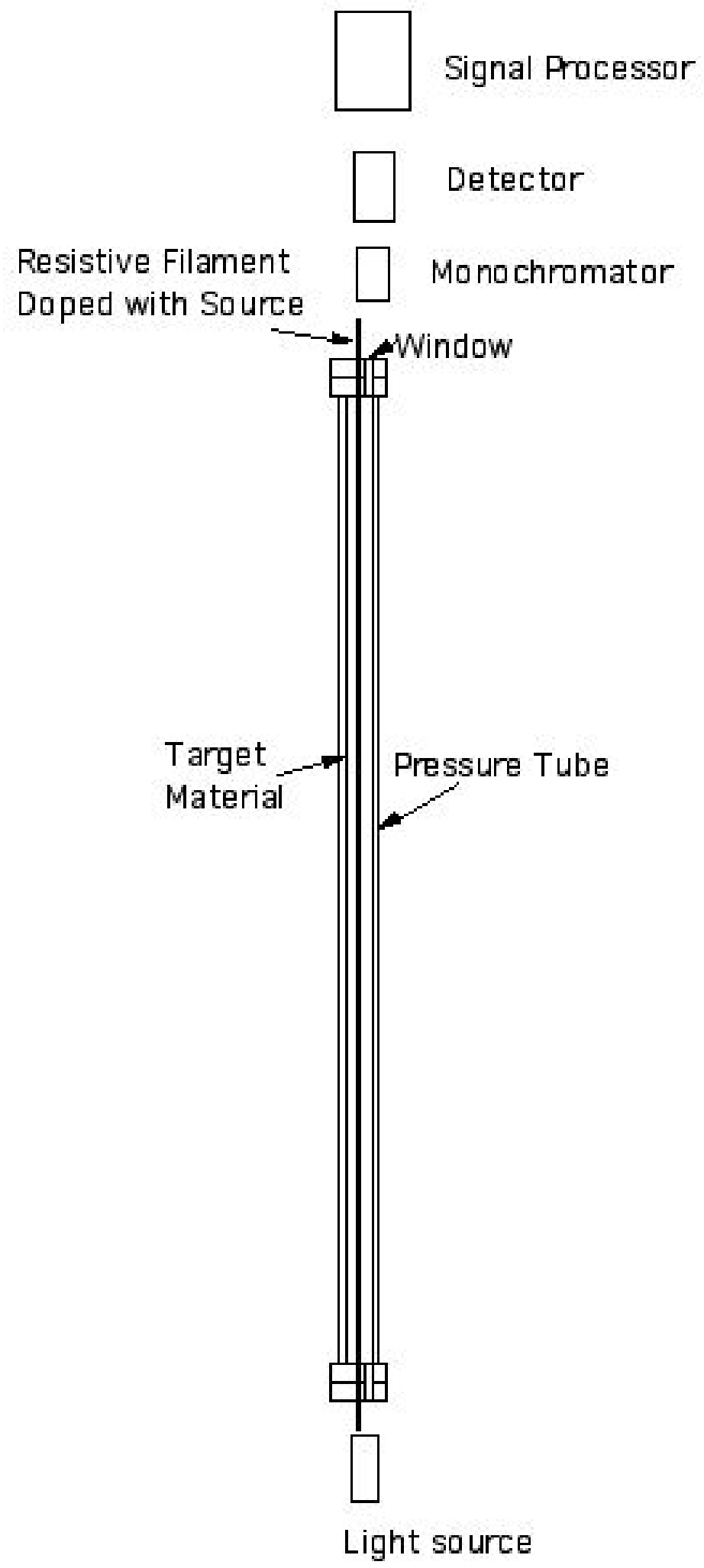

Figure 10. Long Path Atomic Absorption Sorption Detection Concept 


\section{FISSION PRODUCT TRANSPORT TASK: SCOPING AG TEST IN THE SAFETY AND TRITIUM APPLIED RESEARCH FACILITY}

The proposed tests are conceived to offer a flexible platform for scoping tests of Ag vapor sorption and plate-out in reference materials utilizing parts and components that are either available or can be quickly purchased from established vendors (i.e., stock items, no customized parts).

The concept builds from the knowledge that in order to detect the very low quantities of material reported in test specifications (e.g., GA 911095) the system impurities in the gas phase must be maintained as low as technically achievable. This motivates the use of commercial UHV flanges and components commonly referred to as cone-flat systems (for example, Del-SealTM CF from MDC).

The scoping tests proposed offer several advantages:

- Short design/construction time to quickly start scoping tests

- Low cost of replaceable system components

- Natural progression in test complexity with minimal hardware modification

- Capability to perform initial static tests (for isotherms determination) and progressively complex flow conditions (for plate-out behavior)

- Uniform temperature or temperature gradients during operation (up to 3 zones)

- Coupling all proposed diagnostics for surface deposition (tubular sections of reference materials) and residual vapor concentrations in the gas phase (Atomic Adsorption Spectroscopy (AAS), laser adsorption, directly coupled ICP-MS)

- Capability to operate with non-radioactive vapors and radioactive vapors (the Safety and Tritium Applied Research [STAR] facility is a Cat III radiological facility)

- Calibration/optimization platform for in pile tests in ATR

The tests use a long resistive furnace that is available in the STAR lab as part of previous project related to tritium-permeation experiments (Fig.1). The furnace offers 3 independently heated zones that are 12 -in.-long and with up to $2.26 \mathrm{~kW}$ power each. It is currently equipped with a 60-in.-long alumina tube with sealed flanges and helium purging to control oxidation of the internal parts. Test-tube sealed flanges are located outside of the heated zone allowing high-purity conditions and test temperatures in the internal volume up to $1200 \mathrm{C}$. This requires a test tube that is at least longer than the furnace alumina tube, a requirement that is very much compatible with the volume estimated from calculations of $\mathrm{Ag}$ vapor conditions for isotherm tests by Paul Humrickhouse $\left(945 \mathrm{~cm}^{3}\right)$. As shown in Table 2, a test tube with a 1-in. diameter would satisfy the initial test specifications.

Table 2. Required test tube length.

$\begin{array}{lllll}\text { Furnace tube length } & 60 & \text { in } & 152.40 & \mathrm{~cm} \\ \text { Test tube length } & 65 & \text { in } & 165.10 & \mathrm{~cm} \\ \text { Volume } & & & 945.00 & \mathrm{~cm} 3 \\ \text { Inner diameter } & 1.06 & \text { in } & 2.70 & \mathrm{~cm}\end{array}$




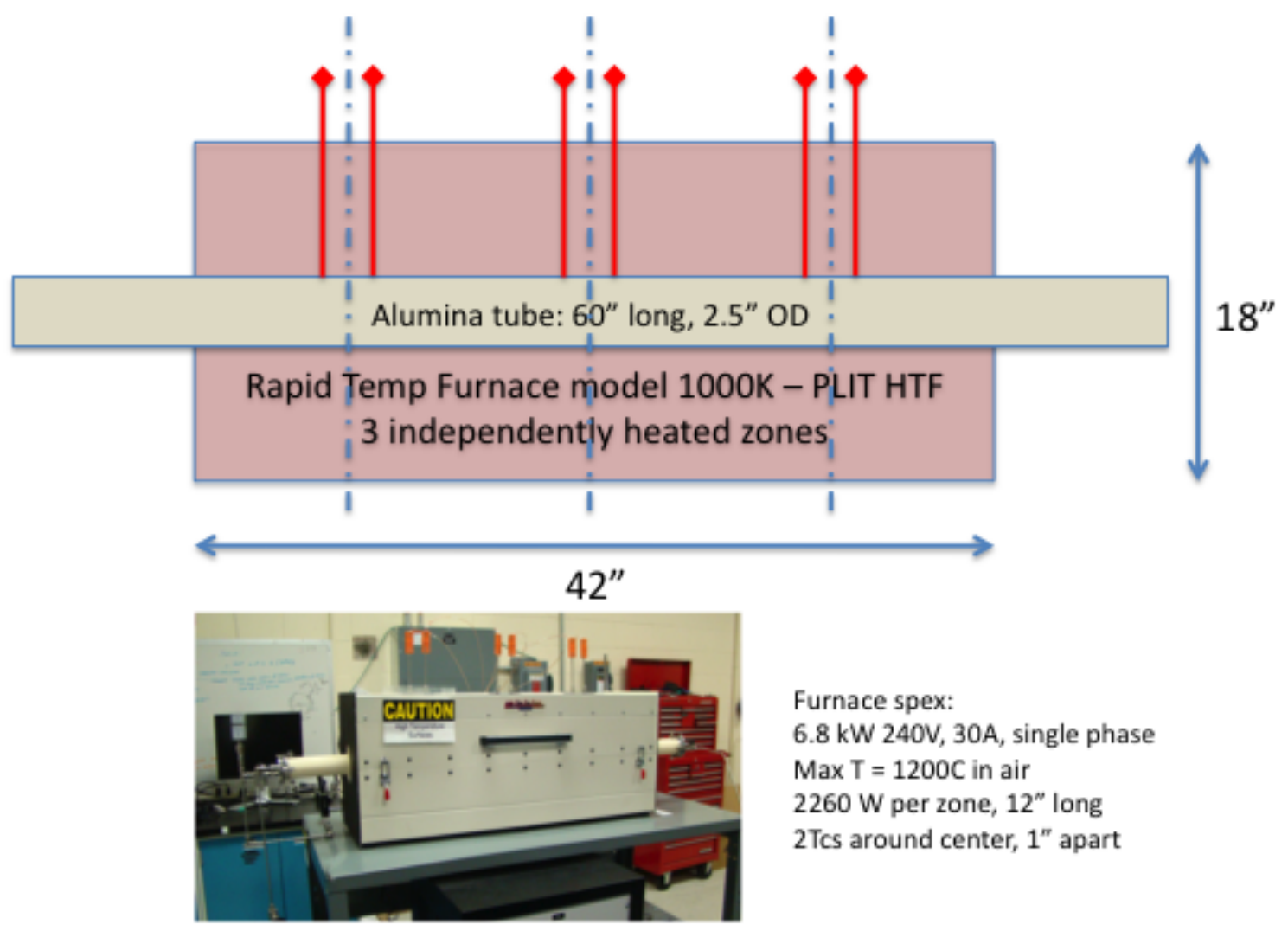

Figure 11. Three-zone tubular furnace

The proposed configuration is similar to that proposed by Jeff Berg for AAS diagnostic testing and its potential application to a test rig in ATR. It also utilizes a Re filament coated with Ag as the source. However, the filaments used are commercial ribbons used for isotopic-ratio mass spectroscopy in thermal ionization systems (data provided by Darin Snyder and John Olson, IRC). They are 0.030 in. wide and $0.001 \mathrm{in}$. thick. The distance between the filament posts is $0.3 \mathrm{in}$. The performance of the filament is shown in Figure 12 in terms of measured surface temperature as a function of filament current, provided by a simple $10 \mathrm{~V}, 10 \mathrm{~A}$ max power supply. The use of commercial filaments simplifies substantially the scoping tests, while the smaller surface area for evaporation does not seem to be a limiting factor giving the very small masses required by test specification. The range and control of the filament current is likely to be a more important factor, and the use of standard and validated components reduces the risk and development time. Furthermore, the 48-in.-long filament may not be technically feasible because the current is known to induce mechanical instabilities (i.e., vibration) that, coupled with progressive embrittlement, would result in a very short lifetime, even without considering the complicated fabrication process required and costs. If a thicker filament (i.e., a rod) is considered, then the issue becomes the current required to achieve desired surface temperature, which would require a low voltage, high amp power supply. 


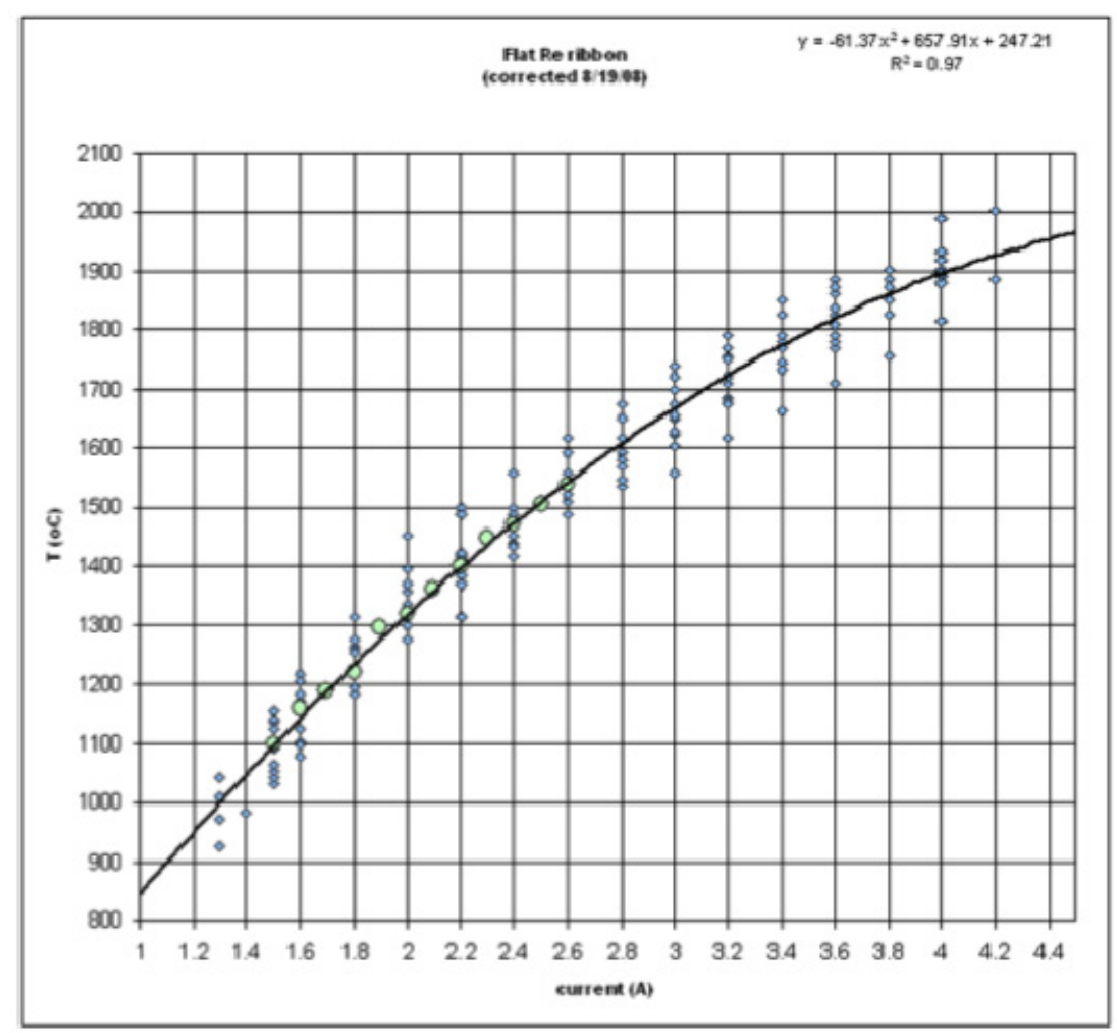

Figure 12. Thermal ionization systems standard filament performance.

The schematic of the test tube used in static He tests (isotherm determination) is shown in Figure 13 and a cross sectional view in Figure 14. The tubular section (1) is about $65 \mathrm{in}$. long and 1 in. diameter and is ended by 2-3/4 standard CF flanges. The filaments (7) are supported by metallic posts (6) made of the same reference materials (i.e., alloy 617) as the collecting tubular sections to measure surface deposition as a function of the distance from the source ( 9 , shown only partially). The posts are sealed with Conax fittings (5) to a double-faced CF flange (2) that is available with two $1 / 4-i n .27$ NPT holes, $120^{\circ}$ apart (shown in cross section view, Figure 14). The fittings may be threaded or welded for improved performance. A similar double sealed flange (10) is used on the tube end with a valve penetration to connect to the UHV pumping system required to achieve the high purity conditions specified. The tube ends are closed by optical windows mounted on CF flanges. Standard materials available include borosilicate glass, quartz $\left(\mathrm{SiO}_{2}\right)$ and sapphire $\left(\mathrm{AlO}_{2}\right)$. The single pass configuration allows a large radial path for the AAS-light or laser beam (8) which is ideal for initial scoping. Multiple pass configurations can be achieved with full (double pass) or selectively transmitting mirrors (infinite passes) on one or both ends. 


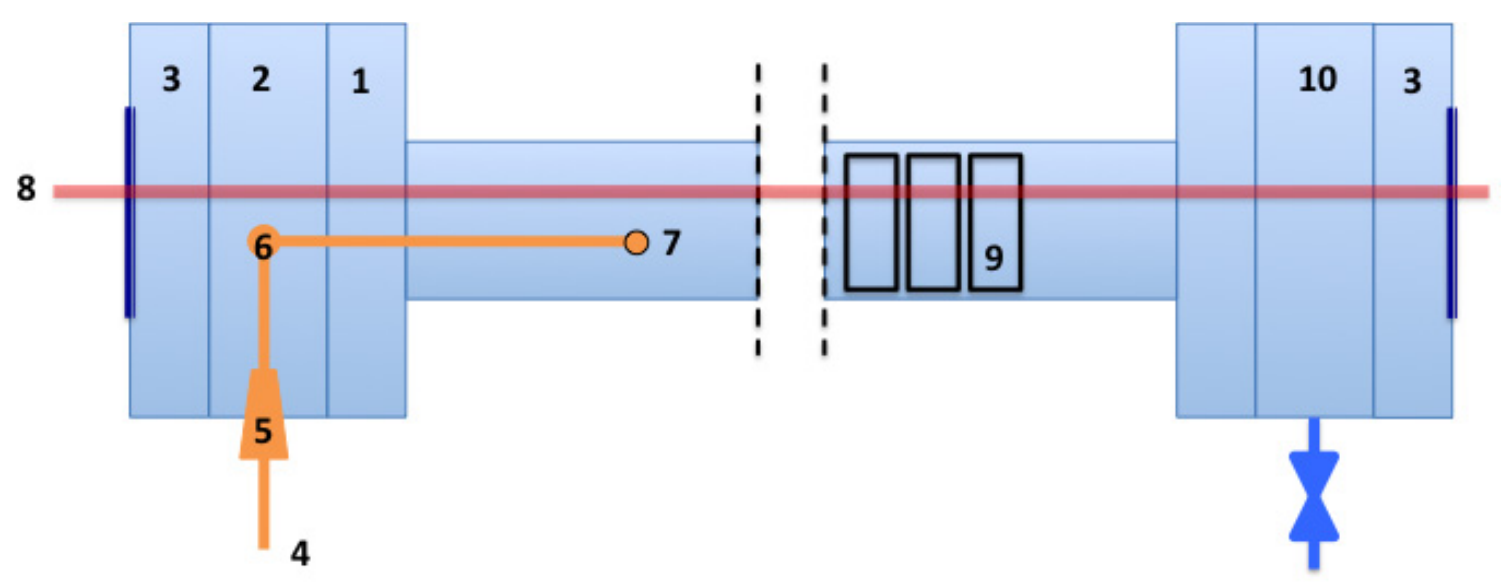

Figure 13. Schematic of static tests for isotherm determination.

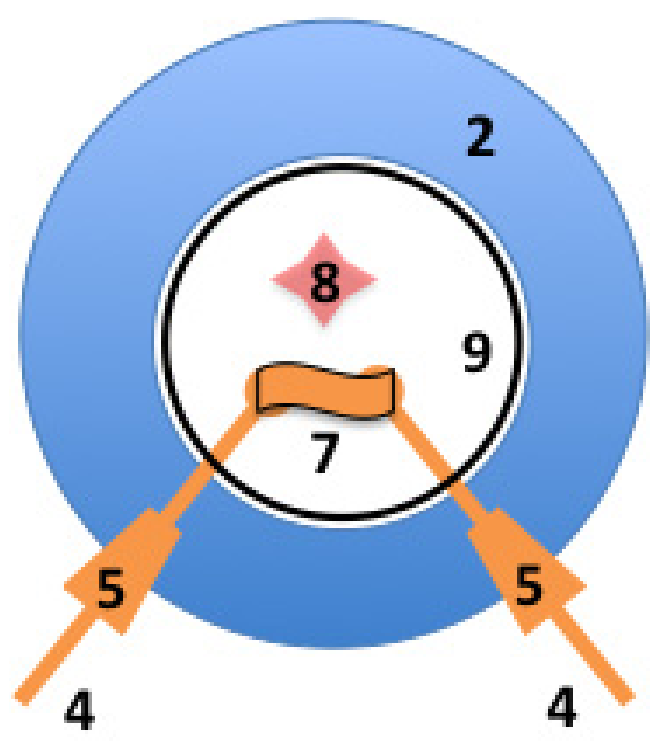

Figure 14. Cross sectional view of static tests for isotherm determination.

Flow conditions will require modification of the test-tube inlet. Simple purge can be achieved by the addition of a welded penetration for He inlet on 2 . This would not modify the light- or laser-beam configuration. However, the fully developed turbulent flows required for adequate plate-out test will require a large circulating capacity and a tailored nozzle design coaxial with the test tube. The beam configuration would then be modified by the addition of a CF tee instead of 2 , with a windowed flange on the single leg and a $90^{\circ}$ mirror located inside the test-tube volume. The large flow at the inlet would minimize the deposition on the mirror surface. 


\section{INL-External Collaborator Conference Call Summary}

A conference call was held March 28, 2011, to discuss experimental concepts for development of isotherm data for sorption of mobile radioisotopes at low partial pressures of $10^{-12}-10^{-15} \mathrm{~atm}$. The concentration range was defined in the test specification for fission product sorption (GA 911095 Hanson). The focus of the concepts is the sorption and desorption of mobile nuclides such as $\mathrm{Cs}, \mathrm{Ag}$, and I on hot-gas duct and intermediate heat-exchanger surfaces in the primary circuit of the high temperature gas reactor design. Due to the nominally continuous release character of Ag from the fuel in the absence of failed particles, Ag-110m has been singled out as the first choice for a single component test sequence.

The participants and their relevant interest in the conference call were:

Izabela Szlufarska, University of Wisconsin (on sabbatical), Modeling of Ag transport and sorption fundamental study of quantum binding energy - relevant to experiment to determine effect of surface condition (oxidation, etc) on measurements. Post-irradiation examination (PIE) analysis usually not precise enough for quantification.

Todd Allen Tyler Gerczak, University of Wisconsin, Ag transport through SiC layer Robert Morris, Oak Ridge National Laboratory (ORNL) Sudarshan Loyalka, University of Missouri, Studying diffusion of Ag in graphite tested with TGA and NAA - mentioned failure of TGA detection in experiments.

Tushar Ghosh, University of Missouri

David Hanson, GA

Jeff Berg, Analytical Chemist, INL

Gary Groenewold, Analytical Chemist, INL

Pattrick Calderoni, INL

Paul Humrickhouse, INL

Brad Merrill, INL

Philip Winston, INL

Gary Groenewold of the INL Interfacial Chemistry group provided a synopsis of the small supercritical oxidation cell approach, in which a source would be vaporized using a laser aimed through a sapphire window in the heated pressure cell, from which the gas phase would be analyzed using secondary ion mass spectrometry (SIMS). It is assumed that the cell would be lined with the target material, either Alloy 617 or $800 \mathrm{H}$, both of which are candidate heat exchanger and duct materials.

David Hanson of General Atomics noted that it with concentrations as low as are specified in his test specification, it seems imperative that measurements be made with radiotracers.

Groenwold responded that the initial tests were intended to verify the detection limits of modern instrumentation, and a combination of gas-phase samples and SIMS analysis would be used to measure the distribution and mass sorbed on the target surface versus the amount released from the source. He acknowledged that at the $10^{-15}$ concentration, he expected radiotracers to be required to be able to meet the detection limit. 
Jeff Berg, of the of the MFC Analytical Laboratory, then described the long-path atomic absorption spectrometry (AAS) technique as it might be applied to a long tube experiment that would be applicable to insertion into a tube furnace. This approach would modify an existing AAS unit with a nominally $2 \mathrm{~m}$ folded beam path with turning mirrors at the end of the test volume. Using a Re-filament source of the type used in isotopic dilution mass spectrometry, the Ag would be vaporized, and the absorption of the light beam in the energy lines specific to Ag would indicate the gas concentration, allowing a live-time measurement of the source as it sorbs onto the target surface.

Hanson commented that one of the problems with static tests like the ones discussed is that the time to equilibrium is low, compared to flowing stream tests. He also noted that it may be difficult to control the oxidation state of the target surface, which is important for cesium and iodine, which preferentially sorb to oxidized and reduced surfaces respectively.

Pattrick Calderoni of INL Nuclear Science and Engineering R\&D Integration then discussed an extension of the long-tube design using an experimental volume 1 in. $(2.54 \mathrm{~cm})$ in diameter by $1 \mathrm{~m}$ long in a zone-controlled tube furnace. The furnace is located at the STAR facility at INL, where the test could be performed using radiotracers to measure distributions and concentrations when the partial pressures are reduced to $10^{-15} \mathrm{~atm}$. The $1 \mathrm{in} . \times 1 \mathrm{~m}$ tube would have a surface area approximately the same as that suggested by calculations done by Paul Humrickhouse.

Paul Humrickhouse of INL Nuclear Science and Engineering R\&D Integration was called upon to give a short exposition on the estimates that he made using the International Atomic Energy Agency (IAEA) TechDoc-978 isotherm information to estimate distributions of the source material between the gas phase and the target surface. His estimates considered different temperatures and partial pressures to evaluate the conditions at which the minimum chemical detection of the ICP-MS of $1 \mathrm{pg}$ would be met. For all conditions, his calculations show that the majority of the mass sorbs to the solid surface rather than remaining in the gas phase.

Hanson responded that it is useful to consider the footnote that for current designs are based on a steam cycle operating at less than $750^{\circ} \mathrm{C}$, with candidate heat exchanger material being Alloy $800 \mathrm{H}$. The direct-cycle, high-pressure, high-temperature $(950 \mathrm{C}, 7 \mathrm{MPa})$ design that was originally proposed by GA would have several materials, including IN100, for the circulator blades.

Philip Winston of INL NGNP program commented on the next step of the progression as a system that would take the $1 \mathrm{~m}$ tube design to a concentric-tube flow system that could be inserted into the ATR to irradiate the target surfaces if that were presumed to be a desired effect. Presumably, neutron-induced dislocations would alter the surface in a way that would affect its sorptivity. This approach would use removable foils or coupons that could be leached or measured by SIMS to determine concentration and distribution. Winston also noted that even in the high-temperature design, the temperatures in the primary duct only are at $950^{\circ} \mathrm{C}$ where it exits the primary containment, and at $350^{\circ} \mathrm{C}$ where it returns to the containment.

Hanson stated that it would not be productive to expose the hot-duct and heat-exchanger material to a neutron flux because the primary containment should provide shielding to prevent exposure. He noted the cost of inserting any experiment into ATR. He also questioned the value of leaching the target foil coupons and the expense associated. Considering the temperature range, Hanson said that for temperatures less than $500^{\circ} \mathrm{C}$, the metal surfaces will act as a perfect sink for Cs and $\mathrm{Ag}$.

Calderoni asked if the cold section would act as a perfect sink. He and Hanson suggested that the real question is with this gradient - how much of the mobile fission product would escape the hot zone - and surmised that virtually all Cs and Ag will deposit on the heat exchanger. There may be problems with plugging at the tube sheet. Hanson also mentioned the need for periodic refurbishment of circulator turbines in the direct cycle design and concern for dose rates on the turbine blades. 
Izabela Szlufarska of the University of Wisconsin wanted to discuss isotherm modeling further with Paul Humrickhouse.

Robert Morris of ORNL commented on the problem of tracer impurities that may affect detection, presumably the possibility of some residual silver contamination on the surface of the Alloy 617 and $800 \mathrm{H}$ high nickel steels.

No significant outcry was noted regarding the possibility of a further conference call, so if discussion is not fulfilled at the NGNP R\&D meeting at the end of April, a final call will be organized to solicit and address comments on an assembled conceptual design.

No extended discussions were held at the Next Generation Nuclear Plant (NGNP) research and development meeting, and no further plans have been made to do further investigations. 


\section{Appendix A ROM Cost Estimate for Small Cell Test Activity}




\section{Appendix A \\ ROM Cost Estimate for Small Cell Test Activity}

Small-Chamber Isotherm Experiments, Proof-of-Principle. Description and Resource Estimate

G. S. Groenewold, 110330

I. Outcome. At the end of these experiments, we expect to

A. Demonstrate the ability to flash volatilize a mass equivalent to one monolayer $\mathrm{Ag}$ in a super critical extraction chamber operated at $\sim 400^{\circ} \mathrm{C}$ and up to 90 atmospheres He.

B. Measure Ag adsorbed to the surfaces of the small chamber, in a manner enabling assessment of the distribution (in)homogeneity of Ag.

C. Evaluate performance of analytical techniques for measuring Ag adsorbed to surfaces of the experimental apparatus.

D. Acquire operational experience handling the small chamber at appropriate pressure and low temperature, in tandem with the laser.

E. Begin to define well the technical difficulties related to measuring radionuclide partitioning at very low partial pressures and surface coverages.

II. Modification of the Small Chamber

A. Source. Initial studies will utilize deposition of a silver salt (e.g. AgNO3) as a dilute solution onto a steel target. Faradaic deposition is a fallback if the dilute solution approach encounters difficulty. The target will be attached to a post that will suspend the target in the middle of the small cell enabling it to be irradiated by the laser beam. The target will be $2-3 \mathrm{~mm}$ in diameter. The target will be disassemble-able, enabling analysis using both leaching-ICP/MS and surface analysis using SIMS.

B. Modification of the cell. A modified supercritical fluid extraction (SFE) cell will be utilized. The cell will be modified by drilling a hole in the interior, that will be filled by the post supporting the target. The cell will also be modified by inclusion of several targets that can be easily removed for surface analysis and by leaching-ICP/MS. A cell vent tube / trap will have to be devised, that will be compatible with sampling using leaching.

C. Laser alignment. An infrared laser will be used to align the optics, which will enable accurate irradiation of the target when switching to a YAG laser, which operates at higher power.

III. Thermal Benchmark

A. It is hypothesized that $\mathrm{AgNO} 3$ will calcine at $400 \mathrm{oC}$ to produce $\mathrm{AgO}$ on the target, but that the Ag will not volatilize / migrate to other locations in the cell.

B. A benchmark study will be compare the effects of $400 \mathrm{oC}$ and 1 atmosphere He with the same temperature, but 90 atmosphere He. 
C. The small chamber will be fitted with a target, then charged with He, heated to temperature, and allowed to stand for a period of time that is still to be determined.

D. The small chamber will be vented and cooled.

E. Analyses

1. Target, to determine how much Ag remains on the surface.

2. Coupons, to determine how much Ag has migrated from the target to the coupon locations.

3. Sapphire windows

4. Small chamber walls

5. Vent gas

IV. Measurement Approaches

A. Surface analysis using secondary ion mass spectrometry (SIMS). The advantages and limitations of SIMS are

1. SIMS can be performed both before and after analyses, since it is effectively nondestructive.

2. SIMS can accommodate only small samples, i.e., would require coupons. But it will be able to handle the target. Both sides of the target will be individually analyzed.

3. SIMS provides spatial distributions over the area of the coupon / target.

4. SIMS provides depth profiling, to determine whether Ag has migrated into a material.

5. SIMS can measure concentrations up to one monolayer, and distinguish this from concentrations greater than a monolayer.

6. SIMS can provide speciation, in the form of co-located atomic emissions, and oxy species such as [AgO]-. SIMS can distinguish nitrate from oxide and metal. The SIMS conclusions can be validated with oxidation state measurements that can be conducted using X-ray photoelectron spectroscopy, on the same samples.

B. Leaching / ICP-MS. The advantages and limitations with leaching / ICP-MS are

1. ICP-MS is a standard analysis with well defined detection limits and is not as affected by matrix effects compared to SIMS.

2. The sampling technique can be used to rinse / leach large areas, enabling the entire surface of the small chamber and the sapphire windows to be sampled.

3. The leaching approach can be used to sample the vent line, providing a means for measuring the residual $\mathrm{Ag}$ in the gas. The assumption here is that the $\mathrm{Ag}$ will plate out on the surfaces of the vent lines, when the He is exhausted into the lower temperature line.

4. There is uncertainty with regard to the efficiency of leaching, and the volume of HNO3 solution that would be required to quantitatively remove the $\mathrm{Ag}$. Dissolution of one 
picogram into one $\mathrm{mL}$ would produce a $1 \mathrm{ppb}$ solution, which would be at the detection limits of the ICP-MS.

5. When combined with coupons, the ICP-MS can provide information on the spatial distribution of the small chamber.

6. A limitation of the ICP-MS is that it provides no information regarding the chemical species that are responsible for sorption.

C. Cross-Comparison, leaching-ICP-MS with SIMS. The two approaches are highly complementary, and serial analyses of the same samples will be conducted.

V. Flash Volatilization by Laser Ablation

A. It is hypothesized that

1. The laser pulse will quantitatively desorb the Ag from the target.

2. The cell walls and coupons will function as a perfect sink in this experiment, but that diffusion will be faster than deposition, and the Ag will be uniformly distributed

B. Laser pulse, $400 \mathrm{oC}, 1$ atmosphere He.

C. Laser pulse, $400 \mathrm{oC}, 90$ atmospheres He.

D. Analyses: see section IV.

VI. Estimated Resources for Small-Chamber Isotherm Experiments, Proof-of-Principle

Total resources are estimated at 10 weeks labor, $\$ 1000$ materials, $\$ 4000$ subcontract for SIMS analyses, and $\$ 1000$ travel for two trips to Montana State to do the SIMS analysis.

A. Safety Envelope

1. LIs exist for both the supercritical extraction cell and the operation of the lasers, therefore we anticipate that this could be put together relatively easily. Still, it will require a committee review.

2. Duration: 4 weeks

3. Resources: labor, 1 week labor

B. Modification of the Small Chamber

1. Modifications are relatively minor. Targets currently used for SIMS can be used as targets for the flash volatilization experiments. Drilling the hole to hold the targets should not be a large expense. Neither should dosing targets. The cell vent tube / trap will have to be designed but may be nothing more than a sparge into HNO3, or a ushaped cold trap.

2. Duration: 2 weeks

3. Resources: 1 week labor 
C. Alignment and targeting of the laser

1. There is extensive experience in this task within the chemistry group, and thus we expect to be able to accomplish this fairly easily. One week of labor is probably overkill, but will provide some contingency, which is important because the laser lab has just moved. We may run the risk of crapping up the sapphire windows, but will not know until we try this.

2. Duration: 2 weeks

3. Resources: 1 week labor

D. Thermal Benchmark

1. The thermal benchmark experiments should be merely a matter of inserting the target, sealing it, purging it with $\mathrm{He}$, and then allowing 30 minutes to equilibrate (arbitrary). Experiment is then vented, and cooled. Subsequently the small chamber will be disassembled, and samples analyzed.

Eventually a study of equilibration time will be required. The follow-on experiment will run at $1260 \mathrm{psi} \mathrm{He}$, and may require procurement of a regulator and a tank of He. If migration of $\mathrm{Ag}$ is observed, then replicate experiments would be suggested. Initially replicate experiments are not anticipated.

2. Duration: 1 weeks

3. Resources: 1 week labor, plus perhaps $\$ 1000$ materials

E. Flash Volatilization by Laser Ablation

1. The flash volatilization experiments will follow the same protocol as the thermal benchmark, only the target will be laser irradiated after the small chamber is brought to temperature and pressure. Conduct of several experiments would be desirable, preferably with a break to enable analytical characterization of the samples generated.

2. Duration: 2 weeks

3. Resources: 2 weeks labor.

F. Analytical Characterization of Samples

1. The flash volatilization (total of 4 ) and the thermal benchmark (total of 2) experiments are expected to generate the same number of samples, viz

a. four coupons for surface analysis and leaching

b. one target for surface analysis and leaching

c. cell rinse

d. window rinse

e. vent line rinse 
The surface analysis samples should be analyzed three times each: before the experiments, after experiments, and after leaching. Thus 15 surface analyses are needed per experiment, times six experiments is 90 surface analyses. That is about $\$ 4000$ at the imaging SIMS facility at the Image and Chemical analysis lab in the Department of Physics at Montana State, and will also require a week of INL labor.

The leaching analysis samples total eight per experiment, times six experiments, for a total of 48 analyses. This is probably the better part of a week of labor at INL.

2. Duration: to be determined

3. Resources: 2 weeks labor, plus $\$ 4000$ instrument charges, $\$ 500$ travel.

G. Interpretation and Reporting

1. Data will have to be reduced and correlated with experiment and location, finally converted into complete sentences. This always takes longer than I think it should.

2. Duration: 2 week.

3. Resources: 2 weeks labor 